\title{
A roda, a prensa, o forno, o tacho: cultura material e farinha de mandioca no litoral do Paraná
}

The wheel, the squeezer, the oven and the 'tacho': the cassava flour material culture in Paraná, Brazil

José Augusto Leandro*

\section{RESUMO}

O presente artigo destaca que a farinha de mandioca constituiu a principal atividade de trabalho e a principal referência alimentar dos trabalhadores rurais da comarca de Paranaguá na segunda metade do século XIX. Com base na análise de um conjunto de inventários do período 1849-1887, é possível afirmar a existência de um modo de vida rural na comarca pautado pela quase onipresença da cultura material da farinha de mandioca.

Palavras-chave: farinha de mandioca; cultura material; comarca de Paranaguá.

\section{ABSTRACT}

This article highlights cassava or manioc flour as the main work activity and food reference for rural workers in the administrative area of Paranagua during the second half of the $19^{\text {th }}$ century. From the analysis of a corpus of inventories postmortem of the period 1849-1887, it is possible to affirm and describe a rural way of life which was almost entirely devoted to the cultivation of cassava flour.

Keywords: cassava flour; material culture; Paranaguá.

\footnotetext{
* Departamento de História da Universidade Estadual de Ponta Grossa (UEPG), Campus Central, Praça Santos Andrade nº 1. 84010-919 - Ponta Grossa - PR - Brasil. jleandroprof@yahoo.com.br.
} 
Ilmo Sr. Juiz de Órfãos

Diz Anna do Carmo, moradora no rio denominado Retiro deste município que tendo ela Suplicante vivido por muitos anos conjuntamente como se casados fossem com José Pereira, tiveram dessa junção sete filhos de nomes Maria, Albino, Anna, Marcelino, Joaquim, José, Antonio, como demonstram as certidões de batismo adjuntas; e como o fruto do comum trabalho adquiriram meios para a compra de uma fábrica de fazer farinha, quatro canoas pequenas, um tacho de cobre e mais objetos grosseiros próprios à serventia doméstica, e bem assim plantaram quatro roças de mandioca, e fizeram uma casa de palha aonde se abrigam e ainda atualmente serve de albergue à Suplicante com seus numerosos filhos. Acontecendo falecer o companheiro e pai dos filhos da Suplicante ficou ela na posse de tudo, não só como meeira que é e legítima proprietária (propriedade ganha com seus próprios braços) como também, porque julga ser incontestável o direito que têm os menores à outra parte desses objetos a que tinha jus seu finado pai: a isso porém se opõe Joaquina Maria do Nascimento, mãe do falecido, e quer assenhorear-se de tudo quanto existe, começando por um tacho do qual não quer fazer entrega...

Paranaguá, 22 de julho de $1859 .^{1}$

O pequeno trecho que narra parte da história de vida de Anna do Carmo, acima descrito, revela, com bastante propriedade, uma trajetória comum à maioria das famílias de lavradores pobres que viveram em algum dos diversos quarteirões que compunham a comarca de Paranaguá no século XIX. ${ }^{2}$ Dos elementos presentes na narrativa do representante legal da viúva, o destaque foi, sem dúvida, a estratégia de sobrevivência do grupo familiar, ligada, de maneira inextricável, à mandioca e à farinha de mandioca. Labutar ao redor da raiz da terra propiciava condições materiais para que uma família, sobretudo com muitos componentes, não transpusesse a barreira que separava a pobreza da miserabilidade, à época.

Neste artigo, que se debruça especificamente sobre o período da segunda metade do Oitocentos na região abrangida pela comarca de Paranaguá, destacamos que a farinha de mandioca constituiu a principal atividade de trabalho e a principal referência alimentar dos trabalhadores rurais. Principalmente dos livres pobres e dos escravos, mas não apenas deles. A partir da análise de um conjunto de inventários do período 1849-1887, mostramos que os 
apetrechos necessários à fabricação da farinha de mandioca foram constantemente citados nos documentos manipulados. ${ }^{3}$ Inventariados com ou sem propriedade cativa no ambiente rural dispunham, no interior de suas unidades agrícolas, da roda, da prensa, do forno e do tacho. Esses utensílios indicam um modo de vida rural na comarca pautado pela quase onipresença da cultura material da farinha de mandioca. ${ }^{4}$

\section{Do CULTIVO DA MANDIOCA}

Com relação ao cultivo da mandioca no Brasil vários autores ressaltam que esta era facilmente adaptável a quase todo tipo de solo, porém era plantada com mais freqüência em solo arenoso, comum nas regiões litorâneas brasileiras. Em Santa Catarina, província do sul do país que mais produzia o produto no século XIX, Laura Hübener assim descreve o cultivo da mandioca:

Para o trato da terra utilizavam o sistema de coivara ou queimada, para logo após revolvê-la com o auxílio da enxada. Sem a aplicação de qualquer outro tipo de adubo, a terra era, em geral, preparada entre os meses de maio e julho, reservando agosto para o início do plantio. Da colheita do ano anterior eram retiradas e guardadas mudas que deveriam medir cerca de 30 a $50 \mathrm{~cm}$ de comprimento e plantadas isoladamente. $\mathrm{O}$ cultivo da mandioca era relativamente fácil, pois exigia mínimos cuidados; raramente era acometida de doenças e pragas. Sua colheita era efetuada após um período de dois anos e geralmente no mês de abril. ${ }^{5}$

Com efeito, não havia muitas variações regionais nas técnicas de plantio da mandioca em diversas partes do Brasil no século XIX. Os lavradores faziam diversas covas no terreno e, em cada uma delas, enterrava-se "uma 'rama' (denominação que se dá à haste da mandioca) que [devia] ficar inclusa no solo uns $10 \mathrm{~cm}$, de maneira levemente inclinada”. ${ }^{6}$ De maneira geral, o cultivo de mandioca, apesar de exigir certo esforço, não implicava trabalho muito árduo.

Vale lembrar que o número de covas para o plantio da mandioca dependia das dimensões do terreno. Na comarca de Paranaguá, durante o Oitocentos, pouquíssimas propriedades poderiam ser classificadas como do tipo plantation. ${ }^{7}$ Nossos dados acerca do tamanho das propriedades na segunda metade do século XIX, a partir dos inventários post-mortem, não diferem dos dados extraídos do registro de terras em pesquisa efetuada por Maria Luiza Baracho. Afirma a autora que a estrutura fundiária de Paranaguá, nesse período, 
era formada basicamente por imóveis que podiam ser considerados de pequeno porte. No período 1854-1857, revela, "a maioria deles não atingia 500 braças e no período 1893-96, as áreas eram, em geral, inferiores a 60 hectares". ${ }^{8}$ Segundo sua amostragem de 184 imóveis para o período 1854-1857, $84,78 \%$ possuíam medidas inferiores a 400 braças. Ainda segundo a autora, as propriedades mais comuns registradas - "sítios" - eram, em sua grande maioria, compostas de unidades entre menos de 50 e até 200 braças (Baracho, 1995, p.91).

Mesmo assim, nas unidades rurais da região em foco, apesar do seu tamanho um tanto diminuto, a produtividade da mandioca não devia ser baixa. O viajante alemão Julius Platzmann refere-se a raízes que mediam três palmos de comprimento e ramas que podiam gerar muitas mandiocas, apesar de raramente atingirem 15 ou mais. ${ }^{9}$

Essa pequena civilização da mandioca tinha a seu favor a facilidade dos lavradores em desenvolver a cultura levando-se em conta o tipo de solo litorâneo, chamado pelo cronista oitocentista Vieira dos Santos de "areento". A mandioca encontrava-se em todos os cantos das baías de Paranaguá e Guaratuba, mas, segundo ele, as plantações que prosperavam "otimamente" ficavam em terras "situadas desde o rumo de Leste a Sul; ou desde as Ilhas do Mel, Raza e Cotinga e em toda a costeira desde a Barra do Sul e Rios de Gurguassu, Correias, Macieis, Almeidas, Taguaré, até o Emboguassu, e inclusivamente até o Rio das Pedras". ${ }^{10}$

Além de assentada em terreno propício, a cultura da mandioca não demandava grandes cuidados, era de fácil trato a todo e qualquer lavrador que encontrasse um quinhão de terra para com ela trabalhar. Barickman destaca que um dos fatores que explica a popularidade da cultura da mandioca no Recôncavo Baiano, por exemplo, era o fato de ela não estar vinculada necessariamente a alguma sazonalidade, como ocorre com outras culturas, embora os meses de março e abril fossem os melhores períodos para se plantar. ${ }^{11}$ Como nos informa Hebe Castro, a mandioca,

apesar de não se constituir em uma cultura permanente, possui a característica de poder ficar até dois anos sem ser colhida após o seu amadurecimento, podendo, portanto, ser literalmente armazenada na própria terra, colhida em função das necessidades do produtor. Seu plantio e sua conservação durante o período de amadurecimento são extremamente simples. As covas podem ser abertas até mesmo com um pau, plantando-se em estacas de 15 a 20 centímetros com dois ou três olhos de broto. A primeira capina só é feita quando começam a brotar os novos pés, repetindo-se a operação duas ou três vezes após o crescimento. De- 
pois que cresce, pouco sofre com a vegetação estranha. Seu amadurecimento leva de oito a 18 meses, podendo depois disso ser colhida até dois anos após. ${ }^{12}$

Mais trabalhosa do que o cultivo da mandioca era a preparação da farinha, que envolvia várias tarefas. Eliminar o ácido venenoso da raiz da mandioca e transformá-la em farinha bruta envolvia seis tarefas: descascar, lavar, ralar, socar, peneirar e torrar (Platzmann, 1872, p.166). Alguns autores apontam que esse trabalho, na maior parte do Brasil, era feito no inverno. Tal período era, por excelência, a época de se farinhar, ou seja, de se produzir a farinha de mandioca (Costa, 1995, p.27).

A forma de se produzir a farinha, diferentemente do cultivo da mandioca, comportava mais variações regionais no Brasil oitocentista, como até hoje. Normalmente, o tipo de produção e a conseqüente qualidade do produto estavam diretamente ligados aos utensílios disponíveis no interior das unidades produtivas.

\section{DOS UTENSÍLIOS PARA FAZER FARINHA}

Se tiveres tão grande falta de dinheiro, e se for tão precário o orçamento da casa, de modo que sejas incapaz com os gastos, mesmo módicos, que exija uma máquina mais simples, pede auxílio ao engenho e desgasta com friç̧ões freqüentes tudo o que o teu pobre campinho tiver produzido numa tábua cujo dorso polido se revista de um pequeno ralo, a ele encostado. Coloca, assim, as raspas obtidas em cestos de junco; e (já que a pobreza cruel impede a fabricação de prensa) faze com que um grande peso estique aqueles cestos pendurados sobre uma alta viga. Torrarás a raspa, finalmente seca, revolvendo-a ao fogo, e logo porás na pobre mesa o mantimento com que se aplacará a dura fome. Isso façam os camponeses desprovidos dos bens que o uso reclama.

José Rodrigues de Melo, De rusticis Brasiliae rebus, 1781.

Quando procuramos identificar o perfil das propriedades das áreas rurais da comarca de Paranaguá, mediante os inventários post-mortem, uma pequena "civilização material da farinha" emerge da documentação. A maior parte das unidades produtivas não dispensava a presença da roda, da prensa, do forno e do tacho, conforme indicado no Quadro 1. 


\section{Quadro 1 - Perfil das propriedades nos inventários rurais da comarca de Paranaguá - 1849-1887}

\begin{tabular}{|c|c|c|c|c|}
\hline Ano & Local & Utensílios & Tipo de produção & Escravos \\
\hline 1849 & Rio Grogussu (Paranaguá) & Roda, prensa, forno, tacho & Farinha & 3 \\
\hline 1849 & Não identificado & Não cita & Roça de mandioca & 7 \\
\hline 1850 & Rio dos Correias (Paranaguá) & Tacho, prensa, forno, roda & Farinha & 12 \\
\hline 1852 & Rio Cubatão (Guaratuba) & Não cita & Não identificado & 2 \\
\hline 1852 & Ilha Rasa (Paranaguá) & Fábrica de fazer farinha, tacho & Farinha & 3 \\
\hline 1854 & Riozinho (Paranaguá) & $\begin{array}{l}\text { Casa de fazer farinha, engenho } \\
\text { de cana, alambique }\end{array}$ & $\begin{array}{l}\text { Farinha, açúcar, } \\
\text { aguardente }\end{array}$ & 12 \\
\hline 1855 & Cassoeiro (Paranaguá) & Roda, prensa, forno, tacho, almofariz & Farinha & 1 \\
\hline 1855 & Rio dos Almeidas (Paranaguá) & Forno e tacho de cobre & Farinha & 3 \\
\hline 1856 & Medeiros (Paranaguá) & $\begin{array}{l}\text { Fábrica de fazer farinha, roda, pren- } \\
\text { sa, forno, tacho }\end{array}$ & Farinha & 7 \\
\hline 1856 & Ijipijessara (Paranaguá) & $\begin{array}{l}\text { Casa com fábrica de fazer farinha, } \\
\text { roda, prensa, forno, cocho, casa de } \\
\text { alambique com duas fábricas, uma de } \\
\text { soque de doze mãos e outra de cana }\end{array}$ & Farinha, aguardente & 7 \\
\hline 1860 & Rio Tagaçaba (Guaraqueçaba) & $\begin{array}{l}\text { Casa de fazer farinha, roda, prensa, } \\
\text { forno, tacho }\end{array}$ & Farinha & 6 \\
\hline 1861 & Rio Descoberto (Guaratuba) & Não cita & Roça de mandioca & 2 \\
\hline 1861 & $\begin{array}{l}\text { Segundo Distrito } \\
\text { (Guaraqueçaba) }\end{array}$ & $\begin{array}{l}\text { Casa de engenho com fábrica, } \\
\text { casa com fábrica de fazer farinha, } \\
\text { alambique }\end{array}$ & Aguardente, farinha & 33 \\
\hline 1863 & Olho d'Água (Paranaguá) & Roda, prensa, forno, cocho & Farinha & 7 \\
\hline 1864 & Tromomo (Guaraqueçaba) & Não cita & Não identificado & 4 \\
\hline 1866 & Rio das Pedras (Paranaguá) & $\begin{array}{l}\text { Moenda, casa de fazer farinha, alam- } \\
\text { bique e capelo }\end{array}$ & Aguardente, farinha & 6 \\
\hline 1866 & Rio dos Almeidas (Paranaguá) & Fábrica de fazer farinha & Farinha & 2 \\
\hline 1868 & Guaratuba & Não cita & Não identificado & 4 \\
\hline 1869 & Bocuhy (Paranaguá) & Roda de ralar mandioca, tachos & Farinha & 1 \\
\hline 1870 & Guaraqueçaba & Fábrica de fazer farinha & Farinha & 1 \\
\hline 1871 & Barra do Sul (Paranaguá) & Roda e prensa & Farinha & 5 \\
\hline 1871 & Tagaçaba (Guaraqueçaba) & Não cita & Não identificado & 3 \\
\hline 1872 & Rio das Pedras (Paranaguá) & $\begin{array}{l}\text { Roda de ralar, forno de cobre } 28 \\
\text { libras }\end{array}$ & $\begin{array}{l}\text { Roça de mandioca e } \\
\text { farinha }\end{array}$ & 8 \\
\hline 1873 & Rio dos Meros (Guaratuba) & $\begin{array}{l}\text { Roda para fazer farinha, forno de } \\
\text { cobre, tacho de cobre }\end{array}$ & Farinha & 5 \\
\hline 1873 & Guaratuba & Roda, prensa, forno & Farinha & 7 \\
\hline 1873 & Saco Tambarutaca (Paranaguá) & Roda, prensa, forno de cobre, tacho & $\begin{array}{l}\text { Farinha, duas roças } \\
\text { de mandioca }\end{array}$ & 7 \\
\hline 1874 & Guaraqueçaba & Não cita & Não identificado & 2 \\
\hline 1874 & Retiro (Paranaguá) & Prensa, forno, tacho, bolandeira & Mandioca e farinha & 6 \\
\hline 1875 & Ponta Grossa (Paranaguá) & Roda, prensa, forno, tacho de cobre & Farinha & 4 \\
\hline 1876 & Rocio Grande (Paranaguá) & Fábrica de fazer farinha, forno, tacho & Farinha & 4 \\
\hline
\end{tabular}


cont. do quadro 1

\begin{tabular}{|c|c|c|c|c|}
\hline Ano & Local & Utensílios & Tipo de produção & Escravos \\
\hline 1878 & Barra do Sul (Paranaguá) & $\begin{array}{l}\text { Fábrica de fazer farinha com roda e } \\
\text { forno de cobre, tacho de cobre }\end{array}$ & Farinha & 2 \\
\hline 1879 & São João Pequeno (Guaratuba) & Roda, prensa, forno, tacho & Farinha & 9 \\
\hline 1880 & Não identificado & Não cita & Não identificado & 1 \\
\hline 1881 & Buquera (Paranaguá) & Engenho de socar & Arroz & 5 \\
\hline 1884 & Guaraqueçaba & Não cita & Farinha & 1 \\
\hline 1879 & Rio do Cedro (Guaratuba) & Alambique, forno de cobre & Aguardente & 6 \\
\hline 1880 & Sítio Retiro (Paranaguá) & $\begin{array}{l}\text { Roda, prensa, forno, tacho, bolan- } \\
\text { deira }\end{array}$ & Farinha & 4 \\
\hline 1881 & Descoberto (Guaratuba) & $\begin{array}{l}\text { Roda de ralar mandioca, forno de } \\
\text { cobre }\end{array}$ & $\begin{array}{l}\text { Farinha, roça de } \\
\text { mandioca, } 200 \\
\text { alqueires de arroz }\end{array}$ & 6 \\
\hline 1881 & Rio Cubatão (Guaratuba) & $\begin{array}{l}\text { Engenho para fabricar aguardente } \\
\text { com casa de palha e pertences, roda, } \\
\text { prensa, forno, tacho }\end{array}$ & Aguardente, farinha & 4 \\
\hline 1881 & Rio das Pedras (Paranaguá) & $\begin{array}{l}\text { Fábrica de fazer farinha com forno e } \\
\text { dois cochos, tachos de cobre, rede de } \\
\text { lancear com cabos e mais pertences, } \\
\text { rancho para depósito de cal }\end{array}$ & Farinha, pescado, cal & 7 \\
\hline 1881 & Itaqui (Guaraqueçaba) & $\begin{array}{l}\text { Engenho para cana com } \\
\text { caldeira,alambique, fábrica para fazer } \\
\text { farinha com roda, prensa e forno }\end{array}$ & Aguardente, farinha & 6 \\
\hline 1881 & Saco Tambarutaca (Paranaguá) & Não cita & Não identificado & 6 \\
\hline 1882 & Bocuhy (Paranaguá) & Não cita & Não identificado & 11 \\
\hline 1882 & Barra do Sul (Paranaguá) & $\begin{array}{l}\text { Fábrica para fazer farinha com roda, } \\
\text { prensa, forno e tacho }\end{array}$ & Farinha & 3 \\
\hline 1883 & Guaratuba & Engenho com casa e acessórios & Aguardente, açúcar & 2 \\
\hline 1884 & Não identificado & $\begin{array}{l}\text { Moenda de ferro, dois alambiques, } \\
\text { forno de cobre }\end{array}$ & Aguardente & 4 \\
\hline 1886 & Imbocuhy (Paranaguá) & $\begin{array}{l}\text { Casa de fazer farinha, roda e prensa } \\
\text { para ralar mandioca com dois fornos }\end{array}$ & Farinha & 9 \\
\hline 1887 & Tagaçaba (Guaraqueçaba) & $\begin{array}{l}\text { Fábrica para farinha, casa para } \\
\text { farinha }\end{array}$ & $\begin{array}{l}\text { Farinha, mandioca, } \\
\text { vigas, milho }\end{array}$ & 1 \\
\hline 1887 & Guaratuba & Engenho de cana & Aguardente, açúcar & 3 \\
\hline
\end{tabular}

Fonte: Inventários post-mortem da comarca de Paranaguá.

Por seu turno, o estudo do perfil da produção dos inventários "mistos", isto é, daqueles que possuíam um relativo equilíbrio entre bens distribuídos no ambiente rural e no ambiente urbano, confirma a presença da "civilização da farinha" no ambiente rural da comarca de Paranaguá na segunda metade do século XIX (Quadro 2). 


\section{Quadro 2 - Perfil das propriedades nos inventários mistos da comarca de Paranaguá - 1849-1887}

\begin{tabular}{|c|c|c|c|c|}
\hline Ano & Localidade & Utensílios & Tipo de produção & Escravos \\
\hline 1849 & Rio Morato (Guaraqueçaba) & Não cita & $\begin{array}{l}\text { "Cultivados" } \\
\text { (mandioca) }\end{array}$ & 16 \\
\hline 1849 & Olho d'Água (Paranaguá) & Prensa, tacho, forno, cocho & Farinha & 6 \\
\hline 1852 & Rio das Pedras (Paranaguá) & Não cita & Não identificado & 30 \\
\hline 1854 & Valadares (Paranaguá) & Não cita & Não identificado & 8 \\
\hline 1855 & $\begin{array}{l}\text { Fazendas Boa Vista e das } \\
\text { Palmeiras (Guaraqueçaba) }\end{array}$ & $\begin{array}{l}\text { Fábrica de fazer farinha, } \\
2 \text { ranchos para depósito } \\
\text { de madeira }\end{array}$ & Farinha, madeira & 38 \\
\hline 1859 & Riozinho (Paranaguá) & $\begin{array}{l}\text { Casa de farinha com roda, prensa } \\
\text { e forno de cobre }\end{array}$ & Farinha & 6 \\
\hline 1860 & Rio Grogussu (Paranaguá) & Casa de fazer farinha & Farinha & 2 \\
\hline 1864 & $\begin{array}{l}\text { Guaraqueçaba (Local não } \\
\text { definido) }\end{array}$ & $\begin{array}{l}\text { Casa com fábrica de fazer farinha, } \\
2 \text { engenhos de serrar madeira }\end{array}$ & Farinha, madeira & 2 \\
\hline 1864 & Serra Negra (Guaraqueçaba) & $\begin{array}{l}\text { Roda, prensa e forno para fabricar } \\
\text { farinha }\end{array}$ & Farinha & 4 \\
\hline 1867 & Tagaçaba (Guaraqueçaba) & Não cita & Não identificado & 2 \\
\hline 1868 & $\begin{array}{l}\text { Rio Guaraqueçaba } \\
\text { (Guaraqueçaba) }\end{array}$ & Engenho e casa de fazer farinha & Farinha & 10 \\
\hline 1868 & Não identificada & $\begin{array}{l}\text { Fábrica de farinha, roda, prensa e } \\
\text { forno }\end{array}$ & Farinha & 7 \\
\hline 1868 & Guaratuba & Não cita & Não identificado & 5 \\
\hline 1868 & Rio Tagaçaba (Guaraqueçaba) & Não cita & Não identificado & 8 \\
\hline 1871 & Rio dos Correias (Paranaguá) & Não cita & Não identificado & 5 \\
\hline 1871 & Rio das Pedras (Paranaguá) & Forno, bolandeira & Farinha & 3 \\
\hline 1877 & Guaraqueçaba & Casa de engenho & Não identificado & 2 \\
\hline 1877 & Itiguassu (Paranaguá) & Roda, prensa, forno & Farinha & 2 \\
\hline 1883 & Guaratuba & $\begin{array}{l}\text { Alambique de cobre, cochos de } \\
\text { madeira, depósito de aguardente, } \\
\text { casa de engenho, bomba de cobre, } \\
\text { cocho para água, pipas, roça de } \\
\text { cana }\end{array}$ & Açúcar, aguardente & 2 \\
\hline 1878 & Não identificado & Alambique, bolandeira & Aguardente & 2 \\
\hline 1873 & Rio Cubatão (Guaratuba) & Não cita & Não identificado & 1 \\
\hline 1876 & $\begin{array}{l}\text { Guaraqueçaba (local não iden- } \\
\text { tificado) }\end{array}$ & $\begin{array}{l}\text { Casa com fábrica de farinha, } \\
\text { engenho de socar arroz; }\end{array}$ & Arroz, farinha & 31 \\
\hline 1876 & Rio Guaraguassu (Paranaguá) & Não cita & Não identificado & 2 \\
\hline 1879 & Barra do Sul (Paranaguá) & Roda, prensa e forno & Farinha & 1 \\
\hline 1880 & Bocahy (Paranaguá) & Fábrica de farinha com pertences & Farinha & 5 \\
\hline
\end{tabular}

Fonte: Inventários post-mortem da comarca de Paranaguá. 
Do total de 74 inventários presentes nos quadros 1 e 2, a farinha de mandioca apareceu articulada com outro tipo de produção (açúcar, aguardente, arroz, madeira, milho, pescado e cal) em 12 documentos; por sua vez, em 38 inventários foi possível identificar somente o cultivo da mandioca e a produção de farinha no interior da unidade rural. Dessa feita, tem-se um total de 50 propriedades (quase $70 \%$ dos documentos analisados com mão-de-obra escrava) cujo cotidiano do trabalho relacionava-se direta ou indiretamente à raiz da terra. E levando-se em consideração que a roda, a prensa, o forno e o tacho pudessem estar no interior das unidades agrícolas pouco tempo antes da chegada do avaliador - para o caso dos inúmeros inventários que não listaram bens materiais -, é provável que a civilização material da farinha abarcasse um número maior de propriedades.

Assim, somando-se os inventários de proprietários de escravos do tipo rural e do tipo misto, não há como negar a existência de certa classe rural produtora de alimentos comercializáveis na comarca na segunda metade do século XIX. Apesar de não dispormos de dados quantitativos de produção das unidades agrícolas, é possível inferir que esta classe, proprietária de escravos, produzia para além da subsistência do seu grupo e de seus próprios cativos. Evidencia-se, também, que essa produção de alimentos concentrava-se, quase que totalmente, em um único produto, a farinha de mandioca. Não cremos também que os excedentes da produção da mandioca e da farinha se dirigissem apenas para os domínios da província. Eles certamente abasteciam o amplo mercado urbano de Paranaguá e subiam a serra, rumo à capital. Mas também não se deve descartar a possibilidade de que essa produção fosse desviada, por contrabando, para outras paragens fora da província, como era o caso da madeira-de-lei na mesma região, na mesma época (Leandro, 2003, p.66-76).

Essa imagem fornecida pelos inventários rurais e mistos da segunda metade do Oitocentos é reflexo de um processo histórico anterior, do final do século XVIII e das primeiras décadas do XIX, quando o quadro das exportações brasileiras ampliou-se, e, em função disso, ampliou-se um mercado interno de produção de alimentos para suprir às crescentes demandas urbanas. Discorrendo sobre essa conjuntura, Schwartz aponta, a partir de pesquisas realizadas para a Bahia, Minas Gerais e São Paulo, a existência de um considerável "emprego de roças de pequena escala e da produção de alimentos com o uso do trabalho escravo". Arrisca o autor:

Há a tentação de afirmar que a escravidão estava se tornando uma instituição mais amplamente difundida em fins do período colonial do que qualquer época 
... os produtores "roceiros" com acesso aos mercados que estavam crescendo nas cidades e no setor da lavoura, parecem ter reagido com o aumento da produção, e o cultivo da mandioca prestou-se à expansão com aumentos principalmente no contingente de trabalhadores. ${ }^{13}$

A interpretação de Schwartz para determinadas partes do Nordeste e do Sudeste deve incluir também o Brasil Meridional. O relatório do capitão governador João Alberto de Miranda Ribeiro, de novembro de 1797, por exemplo, indicou nada menos do que 884 engenhos de mandioca em Santa Catarina. ${ }^{14}$ E, como já apontado por Westphalen, durante o século XVIII a farinha de mandioca foi um importante interciclo colonial situado entre o ouro e a erva-mate no Paraná. ${ }^{15}$ Isso demonstra a importância do produto em diversas partes do sul do Brasil. Nossos dados empíricos indicam claramente que temos, então, um longo período de mais de cem anos no qual a farinha reinou plenamente nos domínios litorâneos no que tange ao abastecimento alimentar da comarca.

Da mesma forma, pode-se afirmar que aqueles que não possuíam cativos, e que muitas vezes estavam mais próximos a um cotidiano de pobreza, também viviam 'presos' à civilização da mandioca. O Quadro 3 identifica o perfil das propriedades nos inventários rurais e mistos da comarca de Paranaguá que não contavam, no seu interior, com a presença de mão-de-obra escrava. Do total de 22 propriedades, 11 delas tinham a mandioca e a farinha de mandioca como principal referência de produção alimentar.

Na região de Capivari, na Província do Rio de Janeiro, Hebe Castro identificou três tipos de beneficiamento da mandioca visando à sua transformação em farinha. Estes eram relacionados aos instrumentos disponíveis no interior das unidades agrícolas e produziam: farinha d'água ou farinha gorda, farinha d'água de mistura e farinha seca. No primeiro tipo, apenas o forno era requerido, sendo primeiramente a mandioca amolecida em água exposta ao sol, espremida à mão e coada em peneira grossa. No segundo tipo, o forno de cobre e a roda de ralar eram indispensáveis: "a mandioca é primeiramente ralada e depois misturada com água, espremida à mão e passada em peneira fina, misturando então o que 'passou' e o que ficou na peneira, de modo a formar novamente uma só massa, de novo espremida e levada ao forno" (Castro, 1987, p.86). No terceiro tipo, entravam em cena os utensílios mais comuns no preparo da chamada "farinha seca": "a mandioca raspada é lavada e ralada em um ralador que pode ser movido à mão ou a água, submetida neste estado durante várias horas à ação de uma prensa, passada em peneira fina e levada ao forno ou tacho para ser cozida e torrada" (Castro, 1987, p.86). 
Quadro 3 - Perfil das propriedades sem mão-de-obra escrava nos inventários rurais e mistos da comarca de Paranaguá - 1857-1884

\begin{tabular}{|c|c|c|c|}
\hline Ano & Local & Utensílios & Tipo de produção \\
\hline 1857 & Barra do Sul & Roda, prensa, forno, tacho & Mandioca, farinha de mandioca \\
\hline 1868 & Rio dos Correias & Roda, prensa, forno & Mandioca, farinha de mandioca \\
\hline 1869 & Grogussu/Cachoeira & Tacho de cobre & Mandioca, lenha \\
\hline 1869 & Ribeirão & Roda, prensa, forno, tacho & Mandioca, farinha de mandioca \\
\hline 1870 & Rio Itiberê & Rede para lancear & Pescado, frutíferas \\
\hline 1871 & Paranaguá (“sítio”) & Forno de ferro, tacho de cobre & Mandioca, farinha de mandioca \\
\hline 1872 & Guaratuba & Engenhoca p/cana, alambique & Aguardente \\
\hline 1873 & Rio Borrachudo/ Rio das Canoas & Engenho e depósito de madeiras & Madeira \\
\hline 1876 & Rio Guaraguassu & Não cita & Não identificado \\
\hline 1876 & Rio Guaraguassu & Não cita & Não identificado \\
\hline 1876 & Sufrague & Não cita & Café \\
\hline 1878 & Brejatuba & Forno, tacho & Mandioca, farinha de mandioca \\
\hline 1880 & Serra Negra & Roda, prensa, forno, tacho & Mandioca, farinha de mandioca \\
\hline 1880 & Serra Negra & Não cita & Não identificado \\
\hline 1880 & Rio Pequeno & Não cita & Não identificado \\
\hline 1882 & Emboguassu & Não cita & Mandioca \\
\hline 1882 & Tagaçaba & Não cita & Não identificado \\
\hline 1883 & Emboguassu & Fábrica de fazer farinha & Mandioca, farinha de mandioca \\
\hline 1884 & Barra do Sul & Fábrica de fazer farinha & Mandioca, farinha de mandioca \\
\hline 1884 & Serra Negra & Casa de cana e alambique & Aguardente \\
\hline 1885 & Embocuhy & Fábrica de fazer farinha, tacho & Mandioca, farinha de mandioca \\
\hline 1887 & Não identificado & Alambique de cobre, forno velho & Aguardente \\
\hline
\end{tabular}

Fonte: Inventários post-mortem da comarca de Paranaguá.

Na Ilha de Santa Catarina, Sandro Costa identificou três tipos de engenho já existentes desde o final do século XVIII: o engenho chamarrita, o engenho de cangalha e o engenho de mastro ou rodete. $\mathrm{O}$ dois últimos eram movidos por tração animal (boi), enquanto o primeiro trabalhava somente com a força humana.

Para a comarca de Paranaguá não identificamos denominações específicas para os tipos de engenho de fabricar farinha existentes. ${ }^{16}$ Porém, a notável ausência de animais no interior das propriedades rurais, salvo raras exceções, como indicam os inventários post-mortem, nos induz a concluir que em nossa região de análise os engenhos provavelmente representassem alguma va- 
riação - provavelmente pouco mais sofisticada - do tipo "chamarrita", que comportava, segundo Costa,

duas peças separadas: a roda sevadeira, a manivela, que é trabalhada, geralmente, por um ou dois indivíduos, e o forno, que possui uma alavanca associada a uma meia roda bolandeira (roda grande) que faz girar, em movimentos alternados para um sentido e para outro (como num movimento de "vai-e-vem") as pás, ou hélice do forno. (Costa, 1995, p.19)

Platzmann nos conta que depois de "colhidas segundo a necessidade", as mandiocas, na baía de Paranaguá, eram transportadas pelos lavradores "sobre a cabeça em cestos de taquara”. Refere-se, então, aos utensílios necessários à fabricação da farinha: a roda, a prensa, o tipiti e o forno. Engenhosamente, alguns lavradores pobres utilizavam como recipiente para a massa da mandioca ralada (que caía para baixo da máquina de ralar) uma canoa fora de uso. Comenta Platzmann que, no processo de manipulação da roda de ralar, os homens adquiriam vigor nos músculos e força no corpo, tomavam um "banho de suor", girando a máquina sem se cansar por horas a fio. Depois de raladas, novas raízes eram lavadas e descascadas. Registra o viajante alemão que essa tarefa, bem como a raspagem da mandioca, feita com facas, eram tarefas femininas. As prensas utilizadas eram feitas de madeiras nobres da região, tampos horizontais longos de 8 pés de comprimento sobre 2 pés de largura e meio pé de espessura. $\mathrm{O}$ tipiti, feito de pedaços de nódulos de taquaruçu, era um cesto cilíndrico de 2 palmos de altura e espessura, e tinha a função principal de retirar o "leite venenoso" da mandioca, conhecido na região como "mantiqueira". Com relação à última tarefa no preparo da farinha, a sua torrefação, Platzmann também sugere que esta era uma tarefa feminina e registra que muitas vezes a massa da mandioca era levada ao forno pela esposa do dono da casa ou sua filha, as quais utilizavam uma pequena concha, denominada "apá", utensílio utilizado para mexer a farinha e evitar que ela queimasse. Após essas tarefas, o "pão diário" estava pronto (Platzmann, 1872, p.166-171).

O costume de se fazer beijus e bolos assados a partir da mandioca também estava presente na comarca de Paranaguá:

Os pequenos ocupantes da casa incomodam um pouco a assadeira. Para eles, $o$ assar bolo é uma festa e a espera monótona. Se o forno não fosse tão alto para os seus bracinhos curtos, eles teriam tirado um beiju há muito tempo debaixo das mãos da mãe. “Deixem-me em paz, meninos!” (Platzmann, 1872, p.166-171) 


\section{TODOS COMIAM FARINHA}

Por conta disso tudo que vimos demonstrando, é possível concluir também que a demanda urbana por farinha de mandioca devia ser enorme. E não apenas a do mercado urbano de Paranaguá, mas também a de mercados de outras cidades paranaenses, especialmente Curitiba. Segundo Carlos Antunes, os habitantes da capital consumiam grandes quantidades de farinha de mandioca do litoral. No jornal O Dezenove de Dezembro de 4 de janeiro de 1871, por exemplo, anunciava-se: "Vende-se 40 sacos de farinha de mandioca recém-chegados de baixo [litoral], a 10 mil réis o saco, para informação nesta tipografia". ${ }^{17}$

A importância que a mandioca e a farinha de mandioca ocupavam no litoral do Paraná por todo o século XIX tem paralelos com o que Barickman identificou para o Recôncavo Baiano no período 1780-1860, a despeito de esta região ser identificada como de plantation, diferente, portanto, da configuração econômica e territorial da comarca de Paranaguá. Entretanto, vale lembrar que as fazendas de mandioca do Recôncavo Baiano foram sempre as fisicamente menores se comparadas às fazendas de cana-de-açúcar e de fumo, e as que utilizavam os menores plantéis de escravos.

O que tornava singular a importância da farinha de mandioca no Recôncavo Baiano, para Barickman, era o fato de o produto representar o principal componente na dieta alimentar dos moradores da região:

Yet no mather how varied or even rich it may have been, the commom diet rested on a few staples. Chief among these was farinha de mandioca. In this regard, the diet of most Bahians resembled that consumed until recently in many agricultural societies. Such a diet typically centers on complex carbohydrates, supplied by one or two cereals or root crops eaten alone or combined with legumes such as beans. Other foods - vegetables, fruits, oils, fats, meat, fish, and spices - may furnish vital nutrients, but their role as a source of calories is secondary. Calories come overwhelmingly from a major staple starch; in Bahia that staple starch was undoubtedly cassava flour..$^{18}$

Tal importância também se evidenciava no fato de que a farinha de mandioca estava presente na mesa tanto de livres como de escravos.

Whether slave or free, most Bahians, even in prosperous times, lived on the margins of subsistance. They survived from one day to the next on the cheapest foodstuffs: 
jerked beef, salted codfish, and above all, farinha. When the price of farinha rose, they could not turn to cheaper substitutes; bread made from imported wheat flour must generally, if not always, have been more expensive. Nor could rice, maize, or beans serve; they never reached the city's market in large enough quantities. Therefore, when faced with higher prices for farinha, most Bahians had no choice; they had to pay. They might buy less meat; they might go into debt; but they bought less farinha only as a last resort. To do so would have meant hunger. ${ }^{19}$

Barickman mostra ainda que o costume de se fazer pão com farinha de mandioca era mais disseminado do que com farinha de trigo, no século XIX. Mesmo levando-se em consideração a existência de algumas padarias (de portugueses e seus descendentes) na cidade de Paranaguá que trabalhavam a partir da farinha de trigo, é muito provável que elas também trabalhassem com a farinha de mandioca. Calcula Barickman que tanto na cidade quanto no ambiente rural cada pessoa consumia uma média de 450 gramas de farinha por dia.

Exemplo do alto consumo da farinha de mandioca na comarca em análise pode ser captado quando da construção de uma embarcação em Paranaguá. A "conta de mantimentos para a gente que se tem empregado no Brigue Cascudo desde o seu princípio até o dia 9 de outubro de 1846", apresentada por Jozé Francisco Barrozo, um dos responsáveis pela construção da embarcação, nos permite visualizar uma média de consumo de alimentos por trabalhador. O documento listou um total de 41 indivíduos livres e 33 escravos que atuaram na construção do referido brigue. Os cativos, porém, trabalharam apenas puxando madeiras do mato e somente em alguns dias santos. Ao calcularmos o consumo de alimentos pelos 41 homens livres, em uma média de 130 dias de trabalho, percebemos que o consumo de carne, 70,5 arrobas, foi excepcionalmente alto. Respondeu por $56,5 \%$ das despesas alimentares da conta apresentada. Tal fato certamente pode ser considerado incomum na comarca. Por sua vez, esses mesmos trabalhadores consumiram um total de 59 alqueires e meio de farinha de mandioca (821,1 litros) responsáveis por quase $20 \%$ das despesas alimentares. A farinha era a principal fonte calórica desses trabalhadores, cujo padrão de consumo alimentar pode ser considerado equivalente ao do Recôncavo Baiano analisado por Barickman, à mesma época. Os outros itens presentes no cardápio dos trabalhadores do brigue Cascudo eram o feijão, o arroz, o toucinho, o charque, a tainha, o sal e o vinho. Representavam, no montante das despesas alimentares, respectivamente $6,6 \%$, $2,9 \%, 9,4 \%, 1 \%, 2,9 \%, 0,3 \%$ e $0,4 \%$. 
Quando da construção do brigue Cascudo, em 1847, o valor do alqueire de farinha de mandioca era de 1 mil e 200 réis. Em 1853 já era bem mais alto: 3 mil e 200 réis..$^{20}$ Quase vinte anos após, em 1872, o alqueire era mais caro ainda, custando em média 5 mil réis. ${ }^{21}$

\section{CONSIDERAÇÕES FINAIS}

A partir dos inventários analisados, com ou sem propriedade escrava, é possível concluir que o principal traço do ambiente rural da comarca de $\mathrm{Pa}$ ranaguá era a vinculação das suas propriedades agrícolas ao cultivo da mandioca e sua transformação em farinha.

A maioria das propriedades inventariadas possuía utensílios relacionados ao mundo da farinha, aquilo que o jesuíta José Rodrigues de Melo chamou, no final do século XVIII, de "bens que o uso reclama".22

Aqueles que não possuíam tais bens - e certamente muitos lavradores pobres da comarca de Paranaguá não dispunham dos utensílios da "civilização da farinha” - provavelmente seguiam a receita do jesuíta e inventavam formas alternativas, mais trabalhosas e menos eficazes para se obter a farinha. Essas formas alternativas de produção não foram captadas na documentação pesquisada.

No mundo rural da comarca de Paranaguá, nas unidades agrícolas de proprietários de escravos e nas unidades agrícolas daqueles que a historiografia rotulou como "livres pobres", foi possível observar a existência de um modo de vida cujo trabalho ao redor da mandioca e da farinha da mandioca encontrou sua expressão máxima. A mandioca garantia os mínimos vitais da população livre pobre e escrava. Estes a tinham como a sua principal referência alimentar, a sua primordial fonte calórica disponível à época. ${ }^{23}$

Era fundamentalmente na lida com a raiz da terra que a vida dos pobres da comarca de Paranaguá, na segunda metade do século XIX, seguia seu curso.

\section{NOTAS}

${ }^{1}$ 1859. Juizo de Órfãos da Cidade de Paranaguá. Autos cíveis de entrega de bens em que é Anna do Carmo supplicante. Museu da Justiça. Os filhos de Anna do Carmo eram menores e haviam nascido em 1843, 1846, 1850, 1853, 1855 e 1857. Um deles não teve anotado $o$ ano do nascimento.

${ }^{2}$ Vasta e diversificada em suas paisagens, a comarca de Paranaguá, na segunda metade do 
século XIX, possuía domínio jurídico e administrativo sobre populações que viviam na cidade de Paranaguá, na vila de Guaratuba (ao sul), e na freguesia de Guaraqueçaba (ao norte). Além disso, também compunham as almas da comarca os moradores de algumas dúzias de quarteirões esparramados por diversas ilhas (Ilha do Mel, Ilha da Cotinga, Ilha Rasa etc.) e outros locais do continente internalizados na Floresta Atlântica, às margens de inúmeros rios.

${ }^{3}$ Os documentos de inventariados constituem um total de 96, sendo 49 inventariados rurais com propriedade escrava, 25 inventariados 'mistos' com propriedade escrava e 22 inventariados rurais e 'mistos' sem propriedade escrava. Os inventários classificados como 'mistos' foram aqueles que trouxeram certo equilíbrio entre bens distribuídos no ambiente urbano e no ambiente rural.

${ }^{4}$ Segundo Jean-Marie Pesez, apesar de a história da cultura material correr o risco de ser apenas uma "retórica da curiosidade", ela possuiu importância fundamental e sempre se mostrará necessária, "porque apresenta o interesse de reintroduzir o homem na história, por intermédio da vivência material ... É o que a história da cultura material proporciona: as condições de trabalho, as condições de vida ou a margem entre as necessidades e sua satisfação. E já que ela é a história dos grandes números e da maioria dos homens, é em primeiro lugar o explorado que ela coloca em primeiro plano”. PESEZ, Jean-Marie. História da cultura material. In: LE GOFF, Jacques. A história nova. São Paulo: Martins Fontes, 2001. p.210-211.

${ }^{5}$ HÜBENER, Laura Machado. O comércio da cidade de Desterro no século XIX. Florianópolis: Ed. da UFSC, 1981. p.78.

${ }^{6}$ COSTA, Sandro Silveira. Os engenhos de farinha de mandioca na Ilha de Santa Catarina: uma perspectiva atual. Florianópolis, 1995. Trabalho de conclusão do curso de História UFSC. p.27.

${ }^{7}$ LEANDRO, José Augusto. Gentes do grande mar redondo: riqueza e pobreza na comarca de Paranaguá, 1850-1888. Florianópolis, 2003. Tese (Doutorado em História) - Programa de Doutorado em História, UFSC.

${ }^{8}$ BARACHO, Maria Luiza Gonçalves. Estrutura fundiária de Paranaguá: 1850-1900. Curitiba, 1995. Dissertação (Mestrado) - UFPR, p.85.

${ }^{9}$ PLATZMANN, Julius. Aus der bai von Paranaguá. Leipzig: Druck und Verlag Von B. G. Teubner, 1872. p.166. As citações de Julius Platzmann foram possíveis graças à tradução de Elizabeth Mengelberg, a quem agradeço.

${ }^{10}$ SANTOS, Antônio Vieira dos. Memória histórica da cidade de Paranaguá e seu município. Curitiba: Museu Paranaense, 1950. v.1, p.89.

${ }^{11}$ BARICKMAN, B. J. A Bahian counterpoint: sugar, tobacco, cassava, and slavery in the Recôncavo, 1780-1860. Stanford: Stanford University Press, 1998. p.167.

${ }^{12}$ CASTRO, Hebe Maria Mattos de. Ao sul da história. Lavradores pobres na crise do trabalho escravo. São Paulo: Brasiliense, 1987. p.84. 
${ }^{13}$ SCHWARTZ, Stuart. Escravos, roceiros e rebeldes. Bauru: Edusc, 2001. p.169.

${ }^{14}$ WESTPHALEN, Cecília Maria. Comércio exterior do Brasil meridional. Curitiba: CD, 1999. p.121.

${ }^{15}$ WESTPHAlEN, Cecília M. As farinhas de Paranaguá. In: PELÁEZ, Carlos Manoel (Coord.). A moderna história econômica. Rio de Janeiro: Apec, 1976.

${ }^{16}$ Nos inventários da comarca de Paranaguá, a expressão "engenho de farinha” foi substituída, pelos avaliadores e escrivães do juizado de órfãos, pelas expressões "fábrica de fazer farinha" ou "casa de fazer farinha". Os engenhos, quando registrados, referiam-se, normalmente, às unidades que beneficiavam cana, arroz e madeiras. Em todo caso, as "casas" ou "fábricas" de fazer farinha eram espécies de engenhos, muitas delas extremamente rústicas.

${ }_{17}$ O Dezenove de Dezembro, 4 jan. 1871, p.3.

${ }^{18}$ A despeito da possibilidade de uma variedade alimentar, a dieta comum dependia de algumas poucas matérias-primas. A principal dentre elas era a farinha de mandioca. Nesse sentido, a dieta de muitos baianos assemelhava-se às de muitas sociedades agrícolas. Tal dieta gira, tipicamente, em torno de algum complexo de carboidratos, junto com um ou dois cereais ou grãos, comido, em combinação ou não, com alguma leguminosa. Outras comidas - vegetais, frutas, óleos, gordura, carne, peixe e especiarias - podiam fornecer os nutrientes essenciais, mas sempre como fonte calórica secundária. As calorias vinham majoritariamente de uma fécula; na Bahia essa fécula era, sem dúvida, a farinha da mandioca. BARICKMAN, 1998, p.45. Tradução livre.

${ }^{19}$ Escravos ou livres, muitos baianos, mesmo em períodos mais prósperos, viviam nos limites da subsistência. Sobreviviam de um dia para o outro com a alimentação mais barata possível: carne seca, bacalhau salgado, e, sobretudo farinha. Quando o preço da farinha subia, a população não encontrava substitutos mais baratos; o pão feito com trigo importado sempre era mais caro. Eram inacessíveis também o arroz, o milho ou o feijão, pois esses nunca chegavam em quantidades suficientes ao mercado da cidade. Assim, quando de uma situação de aumento no preço da farinha, muitos baianos não tinham escolha; tinham de pagar. Podiam comprar menos carne; podiam se endividar; mas comprar menos farinha era a última opção possível. E, nesses casos, isso significava fome. BARICKMAN, 1998, p.53. Tradução livre.

${ }^{20}$ PEREIRA, Magnus Roberto de Mello. Semeando iras rumo ao progresso. Curitiba: Ed. UFPR, 1996. p.34.

${ }^{21}$ SANTOS, Carlos Roberto Antunes dos. História da alimentação no Paraná. Curitiba: Fundação Cultural de Curitiba, 1995, p.130.

${ }^{22}$ MELO, José Rodrigues de. Temas rurais do Brasil. Ponta Grossa, Ed. UEPG, 1997. p.109. Segundo Sérgio Zan e Raul Sozim, tradutores da obra escrita originalmente em latim, José Rodrigues de Melo nasceu no Porto, em 24 de janeiro de 1723, e teve passagem por período de tempo significativo em Paranaguá. "Desconhecem-se os pormenores a respeito dos seus estudos humanísticos e teológicos, que devem ter sido completados, seja como for, no lapso dos dezessete anos que vão de 1739 à data da sua profissão solene, 15 de agosto 
de 1756, no Colégio de Paranaguá, onde talvez já viesse exercendo o cargo de professor de Letras Humanas ... De qualquer forma, é na atividade magisterial em Paranaguá que vai surpreendê-lo a decisão tomada pelo Marquês de Pombal, no sentido inequívoco de cercear a crescente influência política e cultural que a Companhia de Jesus vinha exercendo no Brasil. Constrangido a interromper a sua carreira em terras brasileiras, embarca, em 24 de fevereiro de 1760, para o Rio de Janeiro, onde chegou em 13 de março. Dias mais tarde, juntamente com outros confrades, segue para Lisboa e, de lá, para os Estados Pontifícios. Falece em Roma em 4 de agosto de 1789." (p.15-16).

${ }^{23}$ Segundo SCHWARTZ (2001, p.127), Anna Roosevelt, em Parmana prehistoric maize and manioc cultivation along the Amazon and Orinoco, cita um estudo de 1959, sobre o Brasil, no qual a mandioca produzia 14,2 milhões de calorias por hectare, o milho 4,4, o arroz 3,9 e a batata-doce e o inhame 7,5 milhões de calorias.

Artigo recebido em abril de 2007. Aprovado em dezembro de 2007. 